Berg, B. van den, Yzermans, C.J., Velden, P.G. van der, Stellato, R.K., Brunekreef, B.

Risk factors for unexplained symptoms after a disaster: a five-year longitudinal study in geneyah practice. Psychosomatics: 2009, 50(1), 69-77

\begin{tabular}{|c|c|}
\hline Postprint Version & 1.0 \\
\hline Journal website & http://psy.psychiatryonline.org/cgi/content/abstract/50/1/69 \\
\hline Pubmed link & http://www.ncbi.nlm.nih.gov/pubmed/19213975 \\
\hline DOI & 10.1176/appi.psy.50.1.69 \\
\hline
\end{tabular}

This is a NIVEL certified Post Print, more info at http://www.nivel.eu

\title{
Risk Factors for Unexplained Symptoms After a Disaster: A Five-Year Longitudinal Study in General Practice
}

\author{
Bellis Van den Berg, M.A, C. Joris Yzermans, Ph.D., Peter G. VAN Der Velden, \\ Ph.D., RebecCa K. Stellato, M.S., AND Bert BRUneKReEF, Ph.D.
}

\begin{abstract}
BACKGROUND: Medically unexplained symptoms (MUS) are a common reason to seek medical care. When presented to the general practitioner (GP), more than three-quarters of symptoms such as stomach ache, headache, and pain in bones and muscles cannot be explained by a medical disorder. OBJECTIVE: The authors examined the course of MUS presented to the GP in the 1 year before the disaster and in the 4 years after a disaster in order to study the risk factors for MUS. METHOD: Data were extracted from the electronic medical records of survivors and from a questionnaire $(\mathrm{N}=1,216)$. RESULTS: Although the mean number of MUS was significantly increased statistically in the first 2 years post-disaster, the increase was not clinically significant. CONCLUSION: The authors identified several important risk factors, such as immigrant status and psychological problems, that are easy for GPs to recognize. Despite this, the sensitivity of the regression model was relatively low.
\end{abstract}

\section{INTRODUCTION}

Medically unexplained symptoms (MUS) are a common reason for seeking medical care. When presented to the general practitioner(GP), more than three-quarters of symptoms such as stomach ache, headache, and pain in bones and muscles cannot be explained by presence of a medical disorder. ${ }^{1}$ Despite the lack of a medical diagnosis, these symptoms are associated with impairment in functioning that is similar to that of patients with medical disorders. ${ }^{2,3}$

Patients who present these symptoms to their GP may undergo extensive medical investigations, mostly without any result. ${ }^{4,5}$ Therefore, knowledge of factors that characterize patients with MUS is useful for identification of these individuals before costly tests are done. Factors associated with MUS can be divided into predisposing, precipitating, and perpetuating factors. ${ }^{6}$ Predisposing factors are patient characteristics that make them more at risk for developing symptoms; these include female gender, ${ }^{7-10}$ lower education level, ${ }^{8}$ unemployment, ${ }^{7,9}$ childhood medical illness, and maltreatment. ${ }^{11,12}$ Precipitating factors are events in the person's life, such as stressful life events and psychological problems, which result in the appearance of symptoms. Finally, perpetuating factors are those that maintain or exaggerate symptoms (e.g., financial problems and lack of social support). ${ }^{6}$ 
Berg, B. van den, Yzermans, C.J., Velden, P.G. van der, Stellato, R.K., Brunekreef, B. Risk factors for unexplained symptoms after a disaster: a five-year longitudinal study in geneyah practice. Psychosomatics: 2009, 50(1), 69-77

Although disasters have been described as an important precipitating factor for MUS, studies that focus on MUS among survivors of disasters are rare. ${ }^{14}$ Some health surveys after disasters have reported elevated levels of self-reported physical symptoms among survivors. ${ }^{14,15}$ However, these studies cannot exclude medical disorders as an explanation for the symptoms and might examine symptoms at a different level than studies that examine symptoms presented to the GP. Engel and Katon ${ }^{16}$ described MUS as a four-part process. First, an individual must experience the symptoms, which will be measured on a symptom scale. The second step is the relevant cognition, and it is related to how individuals think about the symptoms. This step includes the beliefs about their cause and the assignment of medical importance. The third step is the individual's seeking medical care for the symptoms, which behavior is mediated by the belief in the significance of these symptoms. The fourth step is the judgment of the clinician as to whether or not the symptom can be explained by a medical disorder. To-date, little is known about MUS among survivors presenting to the GP (Steps 3 and 4). Only one study after a disaster examined unexplained symptoms that were presented to the GP. This study, which was performed 6 years after an airplane crash in Amsterdam, has shown that $57 \%$ to $93 \%$ of symptoms presented to the GP could not be explained by a medical disorder. ${ }^{17}$ However, the course of symptoms over time and the risk factors for MUS presented to the GP were not examined in this study.

On May 13, 2000, a fireworks depot exploded in a residential area in the city of Enschede, The Netherlands. As a result of the explosion and subsequent fire, 23 people were killed, more than 900 people were injured, and approximately 1,200 people were forced to relocate because their houses were destroyed or severely damaged. To study the course of health problems among survivors, the electronic medical records (EMRs) of GPs were used. In the present study, the course of MUS presented to the GP in the 1 year before the disaster and in the first 4 years after the disaster was examined among the total group of survivors and among several subgroups. Also, risk factors were studied for a high level of MUS presented to the GP. Finally, we examined the extent to which the identified risk factors predicted survivors with a high level of symptoms. This information may help GPs to identify individuals at risk for developing MUS.

\section{METHOD}

\section{Study Design and Study Population}

Two data collection methods were combined: a surveillance program in which the electronic medical records (EMRs) of survivors were used, along with a health survey that was taken 3 weeks post-disaster. ${ }^{18-20}$ The Medical Ethical Testing Committee (TNO, Leiden, the Netherlands) approved the study protocol.

All GPs in the city of Enschede were invited to participate in the surveillance program. In the Dutch healthcare system, health insurance is obligatory, and Dutch citizens are required to be registered at the list of one GP whom they consult for their health problems. The GP serves as the gatekeeper for secondary care. In total, 44 of 60 GPs agreed to participate (73\%). The participating GPs had $89 \%$ of all survivors of the fireworks disaster on their list. ${ }^{18}$

Three weeks after the disaster, a health survey was performed in which survivors were asked about their exposure to the disaster and their health problems. All residents of the affected area were invited to participate in the health survey by means of announcements in the local media and letters. In total, 1,567 affected residents (estimated response of about $30 \%$ ) completed the questionnaire. ${ }^{19,20}$ 
Berg, B. van den, Yzermans, C.J., Velden, P.G. van der, Stellato, R.K., Brunekreef, B.

Risk factors for unexplained symptoms after a disaster: a five-year longitudinal study in geneyah practice. Psychosomatics: 2009, 50(1), 69-77

\section{Measures}

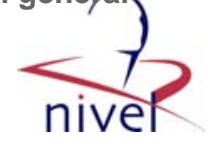

\section{Medically Unexplained Symptoms}

Data on health problems were extracted from the EMRs of survivors from 1 year before the disaster (May 13, 1999) until 4 years post-disaster (May 12, 2004). The registration systems of the participating general practices document the patients' symptoms, examination findings, diagnosis, and interventions in accordance to the International Classification of Primary Care (ICPC), which is compatible with the ICD- $10 .^{21}$ A cluster of symptoms that are likely to remain medically unexplained, such as fatigue, abdominal pain, headache, nausea, and back pain was constructed by one of the authors (CJY). The choice of this cluster was based on studies of increased prevalence rates of physical symptoms after disaster events. ${ }^{14,18,22}$ From previous studies in the general population, we know that the majority of symptoms such as fatigue, headache, back pain, dizziness, and nausea remain medically unexplained after clinical assessment. ${ }^{1,23}$ Symptoms in this cluster were defined as MUS when, in the 1 month after presenting with the symptom, no medical diagnosis had been registered as an explanation for the symptom. The study period was divided into 5 years: from 1 year before until the date of the disaster(Year-1), from the date of the disaster until 1 year post-disaster (Year 1), continuing up to 4 years after the disaster (Years 2 to 4 ).

\section{Potential Risk Factors}

Data on potential risk factors were also available from the EMRs: first, gender, age, and type of health insurance (private versus public), which was used as an indication of socioeconomic status, since higher income is related to private health insurance; second, the number of GP visits in the year before the disaster. Since women visited the GP more often than men, we used different cutoff points for men and women. Male survivors with 8 or more visits and female survivors with 11 or more (80th percentile) visits in the year before the disaster were defined as having a high level of healthcare utilization. Also, a high level of MUS ( $\geq 5$ symptoms; 90 th percentile) in the year before the disaster and any psychological problem presented to the GP in the year before the disaster, as well as any concurrent psychological problems, were selected. These psychological problems belong to a cluster of problems that represent stress reactions, anxiety, and depressive symptoms and disorders, and this cluster has been used in several other studies among the survivors of the fireworks disaster. ${ }^{18,22,24}$

From the health survey, data on education level, employment status (having a paid job), and immigrant status were available. Disaster-related factors were also available from the health survey; for instance, relocation because of a severely damaged or destroyed house, the loss of loved ones, or injury due to the disaster. Also, several questions were asked about what survivors had seen, heard, and felt during the disaster. A scale was compiled for the 29 items; survivors with 18 or more experiences (80th percentile) were defined as having a high level of disaster exposure. Finally, the extent to which survivors experienced psychological distress shortly after the disaster was measured by the total score on the Symptoms Checklist-90 (SCL-90). ${ }^{25,26}$ We dichotomized the scale into High (80th percentile) versus Low scores, according to established references for the healthy Dutch population. ${ }^{26}$

\section{Statistical Analysis}

To study the crude risk factors for MUS, the course of MUS among different groups of survivors - that is, the mean number of symptoms - was calculated for survivors with different demographic characteristics and disaster-related factors.

For the multivariate analysis of potential risk factors, we dichotomized MUS into a high and a low level of symptoms, since the distribution of MUS presented to the GP was highly skewed. Also, since patients who report a high level of symptoms are more likely to attract the clinician's attention, studying risk factors for a high level of symptoms might be more 
Berg, B. van den, Yzermans, C.J., Velden, P.G. van der, Stellato, R.K., Brunekreef, B. Risk factors for unexplained symptoms after a disaster: a five-year longitudinal study in geneyah practice. Psychosomatics: 2009, 50(1), 69-77

useful for clinicians than studying the actual mean number of symptoms. Survivors who nive presented $\geq 5$ MUS to the GP were considered as having a high level of MUS (90th percentile, based on prevalence in Year -1). We examined risk factors for MUS in the 4 years post-disaster (Year 1 to Year 4), using generalized estimating equations (GEE) models. In this study, an unstructured correlation structure was used, which is the least restrictive protocol. ${ }^{27}$

To examine the extent to which the risk factors in the final GEE model predicted a high level of MUS among survivors, we performed multiple logistic-regression analyses for MUS presented to the GP in the 4 years post-disaster. We calculated the observed and predicted survivors with a high level of MUS, as well as the specificity, sensitivity, negative predictive value, positive predictive value, and the total number of correctly predicted cases.

\section{RESULTS}

\section{Study Population}

The study population consisted of 1,216 survivors who participated in the health survey and who were registered in one of the participating general practices at the time of the disaster. Residents who participated in the health survey for whom the EMR was available (Table 1, column 1) were somewhat older, were less likely to have lost a loved one, and less likely to have a high level of disaster exposure than survivors who participated in the health survey but for whom the EMR was not available (Table 1, column 2). Among the survivors for whom the EMR was available, those who participated in the health survey (Table 1, column 1) were more often female, were more likely to have immigrant status, a high number of predisaster GP visits, and a high number of pre-disaster MUS than those for whom the EMR was available but who did not participate in the health survey (Table 1, column 3)

\section{[TABLE 1]}

\section{[TABLE 2]}

\section{[TABLE 3]}

\section{Course of Medically Unexplained Symptoms}

In the 5 years of this study, $21.0 \%$ of all registrations in the EMRs of survivors were related to MUS. The most frequently presented symptoms were back pain, cough, fatigue, neck problems, and shoulder symptoms; these comprised, respectively, $10.3 \%, 5.0 \%, 5.0 \%, 4.6 \%$, and $4.2 \%$ of all MUS presented to the general practitioner.

Table 2 shows the course of MUS in the 5 study years for several subgroups of survivors. In the year before the disaster (Year-1), the survivors reported a mean number of 1.41 symptoms to the GP. Compared with Year -1 , the mean number of MUS was significantly higher in Years 1 and 2 (mean: 1.56 and 1.60, respectively). The mean number of symptoms was increased in Years 1 and 2 among several subgroups of survivors. For example, female survivors reported significantly more MUS to the GP in Years 1 and 2, whereas men did not report a higher number of symptoms in the first 2 years post-disaster.

\section{Risk Factors for a High Level of Medically Unexplained Symptoms in the 4 Years Post- Disaster}

For the multivariate analysis of potential risk factors, we dichotomized MUS into a high and a low level of symptoms (at $\geq 5$ symptoms). In the year before the disaster, $8.3 \%$ of survivors had a high level of MUS. In the 4 years post-disaster (Years 1 to 4 ), this was $9.1 \%$, $9.7 \%, 8.2 \%$, and $9.4 \%$ of survivors, respectively. The results of the final GEE model shows that female gender(OR: $1.4 ; 95 \%$ confidence interval $[\mathrm{CI}]: 1.1-1.8)$, immigrant status (OR: 
Berg, B. van den, Yzermans, C.J., Velden, P.G. van der, Stellato, R.K., Brunekreef, B. Risk factors for unexplained symptoms after a disaster: a five-year longitudinal study in geneyah practice. Psychosomatics: 2009, 50(1), 69-77

1.9; 95\% CI: 1.5-2.5), and public health insurance (OR: 1.7; 95\% CI: $1.2-2.4$ ) were risk factors for a high level of MUS in the 4 years post-disaster (Table 3). Also, a high level of pre-disaster GP visits (OR: 1.8; 95\% CI: 1.3-2.3), as well as a high level of pre-disaster MUS (OR: 5.5; 95\% CI: 4.1-7.4) were related to a high level of MUS in the years after the disaster. In contrast, disaster-related factors, such as relocation and the loss of a loved one, were not related to a high level of symptoms presented to the GP. Finally, concurrent psychological problems appeared to be a strong risk factor for a high level of MUS (OR: 3.9; $95 \%$ CI: 3.1-5.0).

\section{Classification of Observed and Predicted Survivors With a High Level of Medically Unexplained Symptoms}

\section{[TABLE 4]}

Table 4 shows the observed and predicted MUS cases in the 4 years post-disaster, on the basis of the final multiple logistic-regression models for MUS. In Year 1, the model correctly predicted a high level of MUS in $33.7 \%$ of the observed cases. In Years 2 to 4 , the sensitivity of the model decreased $(17.9 \%, 20.2 \%$, and $15.1 \%$, respectively). The specificity of the models was high, indicating that almost all survivors without a high level of MUS were predicted correctly.

\section{DISCUSSION}

This longitudinal study examined the course of and risk factors for MUS presented to the GP by survivors of a disaster. Compared with the year before the disaster, survivors reported a higher mean number of MUS to the GP in the first 2 years afterward. Generalized estimating equations models showed that female gender, immigrant status, public health insurance, a high number of pre-disaster GP visits, and, in particular, a high level of predisaster MUS and concurrent psychological problems were risk factors for a high level of MUS post-disaster. The regression models for Years 1 to 4 had a high specificity, but the sensitivity of the models was relatively low.

Most previous studies among survivors of disasters were cross-sectional and could not study the course of health problems over time. ${ }^{14}$ Despite this, Lima et al ${ }^{28}$ found, in a longitudinal study, a significant decrease in self-reported symptoms 5 years after an earthquake, as compared with 7 months after the earthquake. Another longitudinal study after an earthquake, however, did not find a decrease in symptoms between 3 months and 9 months after the earthquake. ${ }^{29} \mathrm{We}$ can speculate that the prevalence of symptoms only decreased after a longer period of time. In the present study, symptoms were elevated in the first 2 years post-disaster, and the level of symptoms was similar to the baseline level in the third year post-disaster. A previous study among the survivors of the fireworks disaster that included a control group did not show an increase in healthcare utilization and symptoms among control subjects in the 2.5 years post-disaster. ${ }^{18}$ For that reason, we can be relatively sure that the increase in utilization and symptoms among survivors are the effect of exposure to the disaster.

Although the mean number of MUS was significantly increased statistically in the first 2 years post-disaster, this increase in symptoms was not clinically significant. This is in contrast with a study in which the survivors of the fireworks disaster had considerably more self-reported symptoms than a control group. For example, 18 months post-disaster, 33\% of survivors reported $\geq 10$ symptoms, as compared with $20.6 \%$ of control subjects. A previous study among the survivors of the fireworks disaster, as well as studies in the general population, have shown that only a minority of patients seek medical care for their symptoms; this phenomenon has been called "the iceberg of symptoms" (B. van den Berg, unpublished manuscript) ${ }^{30,31}$ This might account for the relatively small increase in the number of symptoms presented to the GP in the present study, indicating that GPs will only 
Berg, B. van den, Yzermans, C.J., Velden, P.G. van der, Stellato, R.K., Brunekreef, B. Risk factors for unexplained symptoms after a disaster: a five-year longitudinal study in geneyah practice. Psychosomatics: 2009, 50(1), 69-77

see a minority of survivors with symptoms. Because the symptoms are strongly related to functional impairment, we believe that GPs should be aware of a higher number of unexplained symptoms among survivors of disasters and should consider MUS before referring the patient to secondary care facilities.

In line with longitudinal studies in the general population, our study showed that baseline, or pre-disaster, MUS was a strong predictor of MUS at a later point in time. ${ }^{32,33}$ The other risk factors, such as female gender and public health insurance (indicating low socioeconomic status $)^{8,11}$ were also comparable with risk factors for MUS in the general population.

Although traumatic events, such as disasters, have been described in the literature as precipitating factors for MUS, ${ }^{13}$ disaster-related factors were not related to a high level of MUS in our study. Psychological problems may mediate the relationship between traumatic exposure and MUS. ${ }^{34}$ In a recent study, we showed that self-reported psychological problems mediated the relationship between trauma exposure and self-reported physical health problems among the survivors of the fireworks disaster (B. van den Berg, unpublished manuscript). Comorbid psychological problems, which are strongly related to MUS in the general population, ${ }^{9,10}$ appeared to be the most important risk factors for MUS among the survivors of the disaster. Since it is more likely that survivors present physical symptoms to the GP than psychological problems, GPs should be alert for psychological problems among patients who present with symptoms such as headache, stomach ache, and back pain.

We identified some risk factors for symptoms presented to the GP. The risk factors that were identified in the present study are easy to recognize for GPs and can be used to identify individuals at risk for a high level of MUS. However, the risk factors are not very specific for MUS and are also risk factors for a high level of healthcare utilization and morbidity in general. ${ }^{35,36}$ With the studied risk factors for MUS, only a minority of survivors with a high level of MUS were identified; in the first year; $33.7 \%$ of survivors with MUS were identified, but this percentage decreased to $15.1 \%$ in the fourth year post-disaster.

It is likely that other factors than the demographic characteristics and previous health measures that were examined in this study will be important in patients' decision to seek medical care for their symptoms. As noted by Engel and Katon, ${ }^{16}$ beliefs about the cause and the attribution of medical importance to the symptoms will mediate the decision to seek medical care. For example, Sensky et al ${ }^{37}$ found that frequent-attenders in general practice had fewer normalizing explanations for their symptoms. Also, Frostholm et al. ${ }^{38}$ found that besides a high number of self-reported symptoms and emotional distress, illness-worry and causal attributions were important predictors of healthcare use. In the present study, we did not measure these illness worries and causal attributions; this might account for the relatively low sensitivity of the regression model.

In the univariate analyses, disaster-related factors appeared to be risk factors for a higher level of MUS as early as 1 year before the disaster. For example, those residents with high level of disaster exposure and those who had their house destroyed reported a higher number of MUS to the GP in the year before the disaster. This can be explained by the fact that the residents of the most affected area were likely to have a public health insurance and an immigrant background, which indicate low socioeconomic status in the Netherlands, and these are risk factors for MUS. After adjusting for public health insurance and immigrant background factors in the multivariable model, there was no significant difference between high and low levels of disaster exposure for the reporting of MUS.

This study has several strengths. First, since disasters are unpredictable events; information on the health status of survivors before the disaster is rarely available. In the present study, electronic medical records of survivors were used, which made comparisons between preand post-disaster symptom levels possible. Pre- and post- measurements are more reliable for studying an increase in symptoms within subjects than comparisons between exposed and nonexposed subjects because other differences between the exposed and nonexposed subjects 
Berg, B. van den, Yzermans, C.J., Velden, P.G. van der, Stellato, R.K., Brunekreef, B. Risk factors for unexplained symptoms after a disaster: a five-year longitudinal study in generath practice. Psychosomatics: 2009, 50(1), 69-77

might bias the results. Second, this study examined the course of health problems up to 4 ivel years post-disaster (medium-term).

Despite these advantages, some methodological considerations should be discussed. First, possible selection bias is of concern in this study. An estimated 30\% of all affected residents participated in the questionnaire health survey, and EMRs were not available for all survivors who participated in the health survey. As compared with the total affected group, participants in the health survey were more likely to be women, living with a partner, between 45 and 64 years old, and more likely to be an immigrant. ${ }^{19}$ Also, participants in the health survey for whom EMRs were available were older, were more likely to have lost a loved one, and have a higher level of disaster exposure than survivors that participated in the health survey but for whom EMRs were not available. These factors were, however, not important risk factors for MUS presenting to the GP. Among the survivors for whom EMRs were available, those who participated in the health survey were more often women, more likely to be immigrants, have a high number of pre-disaster GP visits, and have a high number of pre-disaster MUS than those who did not participate in the health survey. These factors appeared to be important risk factors for a high number of MUS in the years post-disaster. For that reason, it may be possible that the mean number of symptoms is somewhat higher than might be expected in the total affected group.

In a previous study, we examined whether selective response affected the prevalence estimates of health problems. ${ }^{19}$ The results of this study showed that selective response barely affected the prevalence estimates of health problems, indicating that selective response did not result in highly biased prevalence estimates. ${ }^{19}$ Also, pre- and post- measurements were used in the present study, and we believe that selective participation did not bias the statistically significant increase in symptoms within the subjects. Also, we believe that the risk factors for MUS among those in the health survey will not differ substantially from those who did not participate because it is not very likely that the association between MUS and risk factors will be very different among participants and nonparticipants.

Symptoms for which no medical diagnosis was registered in the month after the first presentation of the symptoms to the GP were defined as MUS. In the month after the presentation, the GPs registered a diagnosis for $79 \%$ of the symptoms, leaving $21.0 \%$ unexplained. To examine whether a diagnosis was registered for symptoms after more then 1 month, we did some additional analyses. These analyses showed that in the 2 months after presenting the symptoms, $20.3 \%$ of the symptoms were medically unexplained. In 3 months after presenting the symptom, $20.0 \%$ of symptoms were still unexplained. These results indicate that, for the majority of symptoms, a diagnosis is registered in the first month after presenting the symptom to the GP for the first time. For that reason, we believe that 1 month after symptom presentation is a reasonable cutoff-point for examining MUS.

We cannot exclude the possibility that the levels of symptoms were increased in the 2 years post-disaster because GPs were more aware of MUS after the disaster than before. However, we do not consider this as very likely. In general, somatic complaints among survivors of disasters receive relatively little attention when compared with psychological problems. For that reason, we believe that it is unlikely that GPs are more aware of these physical symptoms. Also, the ICPC allows registration of symptoms at a high level of specificity. The results of a previous study among survivors of the fireworks disaster showed that, as compared with a nonaffected control group, survivors reported considerably more symptoms on a symptom scale. ${ }^{15}$ For these reasons, it is more likely to assume that the higher number of symptoms in the years after the disaster are the result of more symptoms experienced by the survivors than a higher level of awareness in the GP.

In conclusion, the mean number of MUS was elevated in the first 2 years after the disaster and was back to the baseline level in the third and fourth year post-disaster. The increase in symptoms was, however, clinically not significant, reflecting the findings of previous studies that the majority of symptoms in the community are not presented to the GP. The identified risk factors for MUS presented to the GP among survivors were comparable to the risk 
Berg, B. van den, Yzermans, C.J., Velden, P.G. van der, Stellato, R.K., Brunekreef, B. Risk factors for unexplained symptoms after a disaster: a five-year longitudinal study in geneyah practice. Psychosomatics: 2009, 50(1), 69-77

factors for MUS in the general population. The risk factors studied only identified a minoritye all survivors with a high level of MUS. More specific risk factors for MUS should be identified; these may include selective attention and causal attributions. ${ }^{39}$ Also, GPs should be attentive to survivors with MUS because patients will not report all their symptom to the GP although these symptoms are strongly related to functional impairment. Early identification of patients with MUS might prevent extensive medical investigation to detect a medical disorder. Instead, GPs might educate the survivors about possible somatic reactions to traumatic stress. Also, several therapies, such as cognitive-behavioral therapy, have been shown to be effective treatments for MUS. ${ }^{40}$

\section{ACKNOWLEDGMENTS}

We thank the participating general practitioners and their patients, and we thank Dr. H.

Boshuizen (RIVM) for the use of her SAS Macro for Predictive mean matching.

Several research institutes cooperated in this surveillance program: The National Institute for Public Health and the Environment (RIVM), The Institute for Psychotrauma (IvP), the Netherlands Institute for Health Services Research (NIVEL), and the Department of Youth Health Care of the Regional Health Authority (GGD Regio Twente), The Netherlands. The Regional Health Authority was also the coordinator of this program.

This longitudinal study was part of the Health Monitor Survey Victims Firework Disaster Enschede (GGVE) and was performed under the authority of and funded by the Ministry of Health, Welfare, and Sports in the Netherlands.

\section{REFERENCES}

- Kroenke K, Mangelsdorff AD: Common symptoms in ambulatory care: incidence, evaluation, therapy, and outcome. Am J Med 1989; 86:262-266

- Komaroff AL, Fagioli LR, Doolittle TH, et al: Health status in patients with chronic fatigue syndrome and in general population and disease-comparison groups. Am J Med 1996; 101:281-290

- $\quad$ Stewart AL, Greenfield S, Hays RD, et al: Functional status and well-being of patients with chronic conditions: results from the Medical Outcomes Study. JAMA 1989; 262:907-913

- $\quad$ Barsky AJ, Borus JF: Somatization and medicalization in the era of managed care. JAMA 1995; 274:1931-1934]

- $\quad$ Sharpe M, Peveler R, Mayou R: The psychological treatment of patients with functional somatic symptoms: a practical guide. J Psychosom Res 1992; 36:515529

- $\quad$ Walker EA, Unützer J, Katon WJ: Understanding and caring for the distressed patient with multiple medically unexplained symptoms. J Am Board Fam Pract 1998; 11:347-356

- Verhaak PFM, Meijer SA, Visser AP, et al: Persistent presentation of medically unexplained symptoms in general practice. Fam Pract 2006; 23:414-420

- $\quad$ Kroenke K, Spitzer RL: Gender differences in the reporting of physical and somatoform symptoms. Psychosom Med 1998; 60:150-155]

- Kroenke K, Price RK: Symptoms in the community. prevalence, classification, and psychiatric comorbidity. Arch Intern Med 1993; 153:2474-2480

- Feder A, Olfson M, Gameroff M, et al: Medically unexplained symptoms in an urban general-medicine practice. Psychosomatics 2001; 42:261-268

- Hotopf M, Mayou R, Wadsworth M, et al: Childhood risk factors for adults with medically unexplained symptoms: results from a national birth cohort study. Am J Psychiatry 1999; 156:1796-1800

- Walker EA, Gelfand A, Katon WJ, et al: Adult health status of women with histories of childhood abuse and neglect. Am J Med 1999; 107:332-339 
Berg, B. van den, Yzermans, C.J., Velden, P.G. van der, Stellato, R.K., Brunekreef, B.

Risk factors for unexplained symptoms after a disaster: a five-year longitudinal study in geneyah practice. Psychosomatics: 2009, 50(1), 69-77

- $\quad$ Engel CC: Somatization and multiple idiopathic physical symptoms: relationshlp 40 traumatic events and posttraumatic stress disorder, in Trauma and Health: Physical Health Consequences of Exposure to Extreme Stress. Edited by Schnurr PP, Green BL. Washington, DC, American Psychological Association, 2003, pp 191-215

- Van den Berg B, Grievink L, Yzermans J, et al: Medically unexplained physical symptoms in the aftermath of disasters. Epidemiol Rev 2005; 27:92-106

- Van den Berg B, Grievink L, Stellato RK, et al: Symptoms and related functioning in a traumatized community. Arch Intern Med 2005; 165:2402-2407

- $\quad$ Engel CC Jr, Katon WJ: Population and need-based prevention of unexplained physical symptoms in the community, in Strategies to Protect the Health of Deployed U.S. Forces: Medical Surveillance, Record-Keeping, and Risk-Reduction. Edited by Joellenbeck LM, PK Russell, SB Guze. Washington, DC, National Academy Press, 2000, pp 173-212

- Donker GA, Yzermans CJ, Spreeuwenberg P, et al: Symptom attribution after a plane crash: comparison between self-reported symptoms and GP record. $\mathrm{Br} \mathrm{J}$ Gen Pract 2002; 52:917-922

- $\quad$ Yzermans CJ, Donker GA, Kerssens JJ, et al: Health problems of victims before and after disaster: a longitudinal study in general practice. Int J Epidemiol 2005; 34:820-826

- $\quad$ Grievink L, Van der Velden PG, Yzermans CJ, et al: The importance of estimating selection bias on prevalence estimates shortly after a disaster. Ann Epidemiol 2006; 16:782-788

- $\quad$ van Kamp I, van der Velden PG, Stellato RK, et al: Physical and mental health shortly after a disaster: first results from The Enschede Fireworks Disaster Study. Eur J Public Health 2006; 16:252-258

- Lamberts H, Wood M: International Classification of Primary Care. Oxford, England, Oxford University Press, 1987

- $\quad$ Dirkzwager AJ, Kerssens JJ, Yzermans CJ: Health problems in children and adolescents before and after a man-made disaster. J Am Acad Child Adolesc Psychiatry 2006; 45:94-103]

- Kroenke K: Patients presenting with somatic complaints: epidemiology, psychiatric comorbidity, and management. Int J Meth Psychiatr Res 2003; 12:34-43

- Dirkzwager AJ, Grievink L, van der Velden PG, et al: Risk factors for psychological and physical health problems after a man-made disaster: prospective study. $\mathrm{Br} \mathrm{J}$ Psychiatry 2006; 189:144-149

- Derogatis LR, Lipman RS, Covi L: SCL-90: an outpatient psychiatric rating scale, preliminary I. Psychopharmacol Bull 1973; 913-928

- $\quad$ Arrindell WA, Ettema JHM: SCL-90: Handleiding bij een multidimensionele psychopathologie indicator (Dutch). Lisse, The Netherlands, Swets \& Zeitlinger, 1986

- $\quad$ Twisk J (ed.): Applied Longitudinal Data Analysis for Epidemiology: A Practical Guide. Cambridge, UK, Cambridge Press, 2003

- $\quad$ Lima BR, Pai S, Toledo V, et al: Emotional distress in disaster victims: a follow-up study. J Nerv Ment Dis 1993; 181:388-393]

- Wang X, Gao L, Zhang H, et al: Post-earthquake quality of life and psychological well-being: a longitudinal evaluation in a rural community sample in northern China. Psychiatry Clin Neurosci 2000; 54:427-433

- $\quad$ Green LA, Fryer GE, Yawn BP, et al: The ecology of medical care revisited. N Engl J Med 2001; 344:2021-2025

- Hartz AJ, Noyes R, Bentler SE, et al: Unexplained symptoms in primary care: perspectives of doctors and patients. Gen Hosp Psychiatry 2000; 22:144-152

- $\quad$ Clark MR, Katon W, Russo J, et al: Chronic fatigue: risk factors for symptom persistence in a 21/2-year follow-up study. Am J Med 1995; 98:187-195

- Khan AA, Khan A, Harezlak J, et al: Somatic symptoms in primary care: etiology and outcome. Psychosomatics 2003; 44:471-478

- $\quad$ Schnurr PP, Green BL. Understanding relationships among trauma, posttraumatic stress disorder, and health outcomes, in Trauma and Health: Physical Health 
Berg, B. van den, Yzermans, C.J., Velden, P.G. van der, Stellato, R.K., Brunekreef, B.

Risk factors for unexplained symptoms after a disaster: a five-year longitudinal study in geneyah practice. Psychosomatics: 2009, 50(1), 69-77

Consequences of Exposure to Extreme Stress. Edited by Schnurr PP, Green Bप! IVel Washington, DC, American Psychological Association, 2003, pp 247-275

- $\quad$ Campbell SM, Roland MO: Why do people consult the doctor? Fam Pract 1996; 13:75-83

- $\quad$ Dorn T, Yzermans CJ, Kerssens JJ, et al: Disaster and subsequent healthcare utilization: a longitudinal study among victims, their family members, and control subjects. Med Care 2006; 44:581-589

- $\quad$ Sensky T, MacLeod AK, Rigby MF: Causal attributions about common somatic sensations among frequent general-practice attenders. Psychol Med 1996; 26:641646

- $\quad$ Frostholm L, Fink P, Christensen KS, et al: The patients' illness perceptions and the use of primary health care. Psychosom Med 2005; 67:997-1005

- $\quad$ Rief W, Nanke A: Somatization disorder from a cognitive-psychobiological perspective. Curr Opin Psychiatry 1999; 12:733-738

- $\quad$ Kroenke K, Swindle R: Cognitive-behavioral therapy for somatization and symptom syndromes: a critical review of controlled clinical trials. Psychother Psychosom 2000; 69:205-215 
TABLE 1. Comparison of Survivors Who Participated in the Health Survey or Did Not and for Whom the EMR Was Available or Not

\begin{tabular}{|c|c|c|c|}
\hline Characteristic & $\begin{array}{l}\text { Health Survey and EMR Available (Reference) } \\
\qquad N=1,216\end{array}$ & $\begin{array}{c}\text { Health Survey Available/ } \\
\text { EMR } \\
\text { Not Available } \mathbf{N}=\mathbf{3 5 1}\end{array}$ & $\begin{array}{c}\text { Health Survey Not } \\
\text { Available/ } \\
\text { EMR Available } \mathbf{N}=\mathbf{2 , 3 0 2}\end{array}$ \\
\hline Women, \% & 54.1 & 48.7 & $47.6 * *$ \\
\hline \multicolumn{4}{|l|}{ Age, years } \\
\hline $18-24$ & 10.8 & $17.3 * *$ & $17.4 * * *$ \\
\hline $25-44$ & 46.2 & 46.7 & 40.5 \\
\hline $45-64$ & 32.7 & 30.0 & 25.0 \\
\hline$\geq 65$ & 10.3 & 6.0 & 17.1 \\
\hline Low education level, $\%$ & 53.3 & 48.1 & NA \\
\hline Immigrant status, $\%^{\mathrm{a}}$ & 29.0 & 28.0 & $22.6 * * *$ \\
\hline No paid job, \% & 43.3 & 40.3 & NA \\
\hline Relocated, \% & 22.9 & 21.5 & NA \\
\hline Lost a loved one, \% & 5.4 & $8.4 *$ & NA \\
\hline Injury to self, $\%$ & 6.9 & 8.7 & NA \\
\hline High disaster exposure, \% & 18.8 & $24.5 * *$ & 21.1 \\
\hline $\begin{array}{l}\text { High level of disaster } \\
\text { distress, \% }\end{array}$ & 31.6 & 33.6 & NA \\
\hline Public health insurance, $\%$ & 77.7 & NA & 76.7 \\
\hline $\begin{array}{l}\text { High number of pre- } \\
\text { disaster GP visits, \% }\end{array}$ & 22.3 & NA & $13.6^{* * *}$ \\
\hline $\begin{array}{l}\text { High number of pre- } \\
\text { disaster MUS, \% }\end{array}$ & 11.3 & NA & $5.9 * * *$ \\
\hline $\begin{array}{l}\text { Pre-disaster psychological } \\
\text { problems, \% }\end{array}$ & 19.8 & NA & 17.1 \\
\hline
\end{tabular}




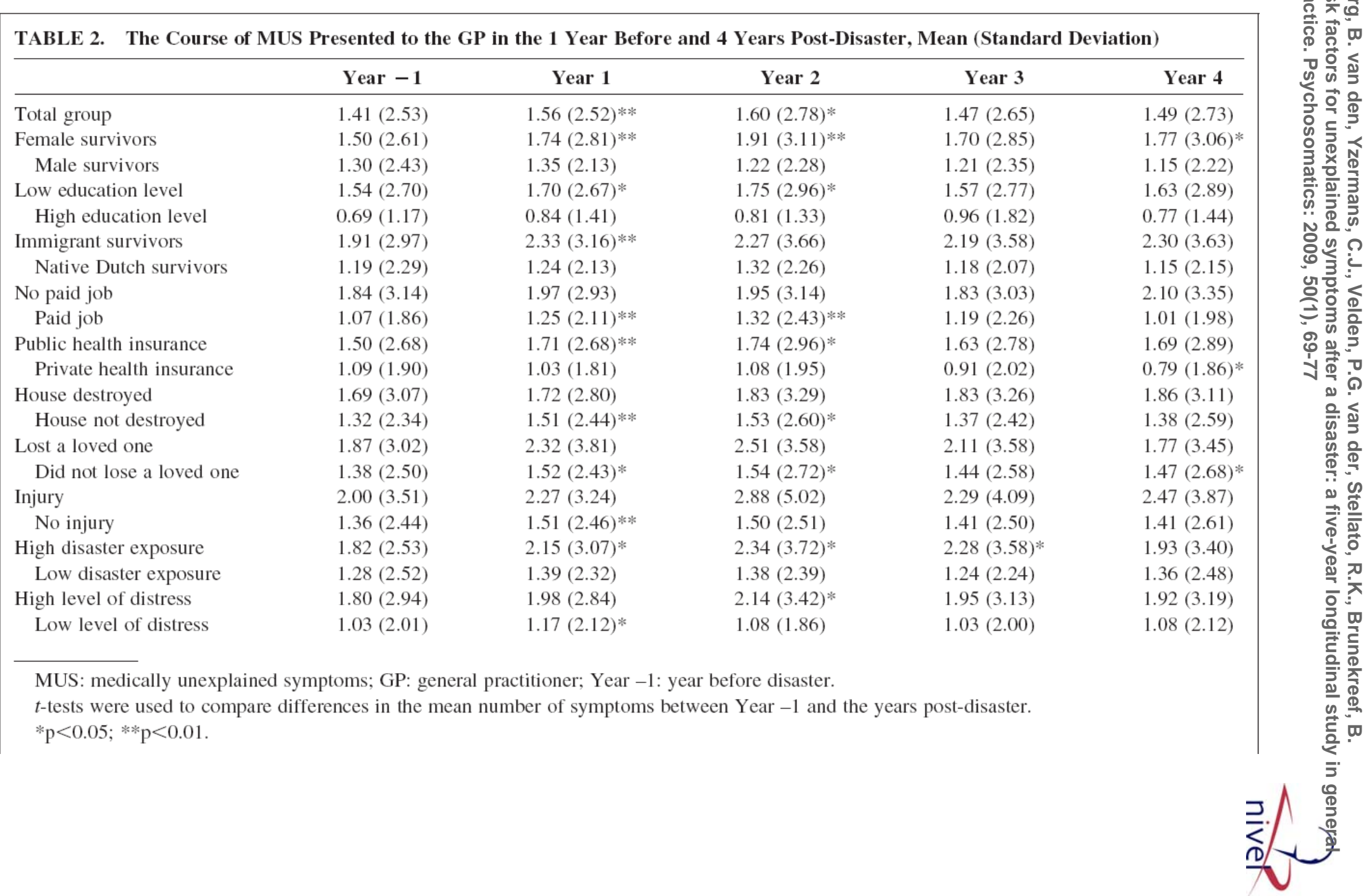


Berg, B. van den, Yzermans, C.J., Velden, P.G. van der, Stellato, R.K., Brunekreef, B.

Risk factors for unexplained symptoms after a disaster: a five-year longitudinal study in geneyak practice. Psychosomatics: 2009, 50(1), 69-77

TABLE 3. Association Between a High Level of MUS in the 4 Years Post-Disaster and Potential Risk Factors

\begin{tabular}{lcc}
\hline & Adjusted OR & $\mathbf{9 5 \%} \mathbf{C I}$ \\
\hline Female gender & 1.5 & $1.1-2.1$ \\
Age (per 10 years) & 1.0 & $0.9-1.1$ \\
Low education level & 1.1 & $0.8-1.6$ \\
Immigrant status & 1.8 & $1.4-2.5$ \\
No paid job & 1.4 & $1.0-1.9$ \\
Public health insurance & 2.0 & $1.3-3.0$ \\
High number of pre-disaster GP & & \\
$\quad$ visits & 2.5 & $1.7-3.6$ \\
High number of pre-disaster MUS & 4.8 & $3.3-7.0$ \\
Pre-disaster psychological problems & 1.1 & $0.8-1.6$ \\
Relocated & 0.7 & $0.5-0.9$ \\
Lost a loved one & 1.6 & $0.9-2.6$ \\
Injury to self & 1.4 & $0.8-2.4$ \\
High disaster exposure & 1.3 & $0.9-1.7$ \\
High level of self-reported distress & & \\
$\quad$ post-disaster & 1.4 & $1.0-1.9$ \\
Psychological problems (concurrent) & 3.4 & $2.6-4.4$ \\
&
\end{tabular}


TABLE 4. Classification of Observed and Predicted Survivors With a High Level of MUS in the 4 Years Post-Disaster

\begin{tabular}{|c|c|c|c|c|c|c|c|}
\hline \multirow[b]{2}{*}{ Observed Cases } & \multicolumn{4}{|c|}{ Predicted Cases } & \multirow{2}{*}{$\begin{array}{c}\text { Positive } \\
\text { Predictive Value } \\
\end{array}$} & \multirow{2}{*}{$\begin{array}{c}\text { Negative } \\
\text { Predictive Value }\end{array}$} & \multirow{2}{*}{$\begin{array}{c}\text { Total } \\
\text { Correctly Classified } \\
\end{array}$} \\
\hline & Yes & No & Sensitivity & Specificity & & & \\
\hline \multicolumn{8}{|l|}{ MUS Year 1} \\
\hline Yes & 33 & 65 & $33.7 \%$ & $98.0 \%$ & $63.4 \%$ & $93.5 \%$ & $92.1 \%$ \\
\hline No & 19 & 939 & & & & & \\
\hline \multicolumn{8}{|l|}{ MUS Year 2} \\
\hline Yes & 19 & 87 & $17.9 \%$ & $98.7 \%$ & $61.3 \%$ & $91.5 \%$ & $90.6 \%$ \\
\hline No & 12 & 1,025 & & & & & \\
\hline \multicolumn{8}{|l|}{ MUS Year 3} \\
\hline Yes & 19 & 75 & $20.2 \%$ & $98.9 \%$ & $63.3 \%$ & $92.7 \%$ & $91.9 \%$ \\
\hline No & 11 & 951 & & & & & \\
\hline \multicolumn{8}{|l|}{ MUS Year 4} \\
\hline Yes & 16 & 90 & $15.1 \%$ & $99.1 \%$ & $64.0 \%$ & $91.3 \%$ & $90.6 \%$ \\
\hline No & 9 & 941 & & & & & \\
\hline $\begin{array}{l}\text { There was no e } \\
\text { MUS: medicall } \\
\text { (model); specifici } \\
\text { value: usefulness } \\
\text { without MUS. }\end{array}$ & $\begin{array}{l}\text { ice of } \\
\text { explai } \\
\text { easur } \\
\text { e test }\end{array}$ & $\begin{array}{l}\text { ck of fit } \\
\text { symptor } \\
\text { the pr } \\
\text { del in c }\end{array}$ & $\begin{array}{l}\text { any of the se } \\
\text { sensitivity: } m \\
\text { tion of peopl } \\
\text { ifying peopl }\end{array}$ & $\begin{array}{l}\mathrm{d} \text { models acc } \\
\text { ared by the } \mathrm{p} \\
\text { hong those wl } \\
\text { h MUS; neg }\end{array}$ & $\begin{array}{l}\text { ng to the Hosmer a } \\
\text { rtion of people wit } \\
\text { o not have MUS w } \\
\text { predictive value: }\end{array}$ & $\begin{array}{l}\text { emeshow test. } \\
\text { JS who also have a } \\
\text { ive a negative test (r } \\
\text { Iness of the test/ m }\end{array}$ & $\begin{array}{l}\text { tive result for the test } \\
\text { l); positive predictive } \\
\text { in classifying people }\end{array}$ \\
\hline
\end{tabular}

There was no evidence of a lack of fit in any of the selected models according to the Hosmer and Lemeshow test.

MUS: medically unexplained symptoms; sensitivity: measured by the proportion of people with MUS who also have a positive result for the test without MUS.
a 